\title{
Conditions of synthesis and structure of metakaolin-based geopolymers: application as heavy metal cation sorbent
}

\author{
Magdalena Król', Kamila Brylewska ${ }^{1,2, ~ ", ~ A r k a d i u s z ~ K n a p i k ~}{ }^{1}$, Kamil Kornaus ${ }^{1}$, \\ Włodzimierz Mozgawa ${ }^{1}$ \\ ${ }^{1}$ AGH University of Science and Technology, Faculty of Materials Science and Ceramics, al. Mickiewicza 30, \\ 30-059 Kraków, Poland \\ ${ }^{2}$ Jagiellonian University, Faculty of Chemistry, Ingardena 3, 30-060 Kraków, Poland \\ "Corresponding author: e-mail: kamilaaa@agh.edu.pl
}

\begin{abstract}
This study presents the synthesis of geopolymer materials designed for application as self-supporting zeolite membranes. For this purpose, batches of metakaolin activated with sodium silicate and sodium hydroxide were used. During synthesis, it was assumed that low temperatures are sufficient to receive the membranes. The composition of raw materials and temperature of activation were selected in such a way so as to correspond to the basic chemical compositions and synthesis conditions of sodalite as well as zeolites A and X. Additionally, the structural and textural properties of geopolymers were determined. The results show that it is possible to obtain composite zeolite structures in an amorphous matrix. A number of synthesized materials were used in the sorption of selected heavy metal cations $\left(\mathrm{Ni}^{2+}, \mathrm{Zn}^{2+}, \mathrm{Pb}^{2+}\right.$ and $\left.\mathrm{Cd}^{2+}\right)$. It was concluded that the investigated geopolymerization process may be applied to obtain a material with potential use as a heavy metal sorbent.
\end{abstract}

Keywords: metakaolin, geopolymers, structural and textural properties, heavy metal sorbent.

\section{INTRODUCTION}

Geopolymers are inorganic polymers that belong to a group of amorphous aluminosilicates with structural elements similar to those of crystalline zeolites. Their 2- or 3-dimensional structure is based on alumina $\left[\mathrm{AlO}_{4}\right]$ and silica $\left[\mathrm{SiO}_{4}\right]$ tetrahedra joined together with oxygen atoms. The negative charge of $\left[\mathrm{AlO}_{4}\right]$ is compensated by the presence of alkali metal ions (e.g. $\mathrm{Na}^{+}$or $\mathrm{K}^{+}$).

Geopolymers synthesis (geopolymerization) involves chemical reaction between alumina and silicate rich materials in the presence of alkali activators, i.e. $\mathrm{NaOH}$, $\mathrm{KOH}$ or water glass. This exogenous process gives rise to oligomers (dimers and trimers) which are proper structural units of geopolymers. Those units create dimensional framework ${ }^{1}$. Exact course of geopolymerization depends mainly on the nature of both aluminosilicates and alkali reagents, ion-exchange capacity and the structure of the precursor materials. Nevertheless, most investigators concur that the formation of geopolymers involves the dissolution of aluminum and silicon compounds present on the surface of aluminosilicates, the polymerization of active surface groups, and the formation and eventual curing of gel$^{2}$.

Owing to high content of $\mathrm{Al}$ and $\mathrm{Si}$, natural materials such as clay but also fly ash and blast furnace slag are often used to synthesize geopolymers. Due to the presence of numerous contaminants, those reactants do not suit purpose of model surveys. For this reason, kaolin or preferebly its metastable and dissordered form - metakaolin is used instead. Transormation of kaolin into metakaolin takes place at $550-800^{\circ} \mathrm{C}$ and involves dehydroxylation of strongly bound hydroxyl ions in $\mathrm{Al}$ layers, which leads to layered structure ${ }^{3-5}$ and further to geopolymer's mechanical properties improvement ${ }^{6-9}$.

Additives other than metakaoline or kaoline are also used in the synthesis of geopolymers, including calcium hydroxide, slag or ash. They are active as binders and builders in the geopolymer matrix, but do not significantly affect the deterioration of the final products ${ }^{10-11}$.

Geopolymers properties are determined by the selection of the reagent used, which is associated with availability, cost, and the potential applications of the product. The quality of the produced geopolymer is also affected by the type and concentration of the alkali activator, drying temperature and time of polycondensation. Sodium and potassium hydroxide are the most common alkalis ${ }^{7}$. Several studies confirmed their high compressive (after exposure to a pressure of over $90 \mathrm{MPa}$ for 28 days) and flexural (10-15 MPa) strength, resistance to weather conditions, low porosity, and little shrinkage ${ }^{12}$. As a consequence, geopolymers are used in the construction industry, chemical engineering, environmental protection, and as additives to cements or alkali-slag binders ${ }^{13}$. Research was also conducted on the fire, frost, acid, sulphates, and seawater resistance of materials based on metakaolinite and fly ash ${ }^{14}$.

One of the application spectrum of geopolymers is environment protection. The ongoing degradation of natural environment, connected mostly with human activity, has been a significant influence for some time now. The contamination of water and air is connected mainly to the presence of heavy metal cations. For this reason materials with advantageous sorption properties are highly desired. Geopolymers are environmentally friendly materials, used as adsorbents of heavy metal cations ${ }^{15}$. There are many studies ${ }^{16-17}$ showing that geopolymers are characterized by high porosity and capacity and therefore they are used in immobilization of heavy metals to removal them from aqueous solution. For example Yuanyuan $\mathrm{Ge}^{16}$ described synthesis of porous geopolymeric spheres by a solidification method and their use as adsorbents for the removal of $\mathrm{Cu}$ (II) from aqueous solution. Zhang et al. ${ }^{18}$ studied geopolymers based on fly ash and immobilized $\mathrm{Cr}^{6+}, \mathrm{Cd}^{2+}$, and $\mathrm{Pb}^{2+}$ ions and Yousef ${ }^{19}$ studied the impact of zeolitic tuffs on 
the adsorption capacity of geopolymer products. It was confirmed that this material can have high adsorption capacity regarding methylene blue and $\mathrm{Cu}^{2+}$. Other studies $^{\mathbf{2 0}}$ based on the synthesis of geopolymers from metakaolin and silica fume and it's use as adsorbents for decontamination of $\mathrm{Cs}^{+}$and $\mathrm{Pb}^{2+}$ ions.

The aim of this work was to study the influence of the synthesis conditions (chemical composition of substrates and activation temperature) on the structure of synthesized geopolymers. Additionally, the purpose of this work was to obtain zeolite phases in the stable geopolymer matrix. Geopolymers have similar structure to zeolites, and they are often referred to as zeolitic precursors. This paper also examines the correlation between the structure of the obtained geopolymers with their sorption properties towards heavy metal cations $\left(\mathrm{Ni}^{2+}, \mathrm{Zn}^{2+}, \mathrm{Pb}^{2+}\right.$ and $\left.\mathrm{Cd}^{2+}\right)$.

\section{EXPERIMENTAL}

\section{Material preparation}

Kaolin, a raw clay material, which had been extracted from the Maria III national polish deposit, was used in the study. Kaolin was calcined at $800^{\circ} \mathrm{C}$ for $2 \mathrm{~h}$ in a chamber furnace to obtain metakaolin. Its chemical composition (recalculated to oxides), determined by XRF (WDXRF, Axios max 4kW, PANalytical), normalized to $100 \%$ was follows (in wt.\%): $58.50\left(\mathrm{SiO}_{2}\right), 39.23\left(\mathrm{Al}_{2} \mathrm{O}_{3}\right)$, $0.72\left(\mathrm{Na}_{2} \mathrm{O}\right), 0.61\left(\mathrm{Fe}_{2} \mathrm{O}_{3}\right), 0.61\left(\mathrm{TiO}_{2}\right), 0.14(\mathrm{MgO}), 0.09$ $(\mathrm{CaO}), 0.01\left(\mathrm{~K}_{2} \mathrm{O}\right)$.

Metakaolin was activated with a solution of sodium silicate (39 wt. $\%$ of $\mathrm{SiO}_{2}$ and $\mathrm{Na}_{2} \mathrm{O}, \mathrm{SiO}_{2} / \mathrm{Na}_{2} \mathrm{O}$ (molar ratio $=2.5, \mathrm{POCH}$ ) and sodium hydroxide (pure $\mathrm{NaOH}$, $\mathrm{POCH})$ in order to receive zeolite structures in an amorphous geopolymer matrix. Two series of samples (A and B) with different $\mathrm{SiO}_{2} / \mathrm{Al}_{2} \mathrm{O}_{3}$, and the same $\mathrm{Al}_{2} \mathrm{O}_{3} / \mathrm{Na}_{2} \mathrm{O}$ and $\mathrm{H}_{2} \mathrm{O} / \mathrm{Na}_{2} \mathrm{O}$ molar ratios were prepared. Two different temperatures of sample activation ( $\mathrm{T}_{\text {activation }}$ is the same as curing temperature) - $368 \mathrm{~K}$ (A series) and $353 \mathrm{~K}$ (B series) - were applied, since geopolymer polycondensation requires the external provision of energy ${ }^{\mathbf{1 3}}$. Geopolymerization reaction is endothermic process. The time of activation was $24 \mathrm{~h}$. During synthesis, it was assumed that low temperatures are sufficient to receive the membranes, and that standard high-temperature processes used in the ceramic industry, such as sintering or firing, are not required. The conditions of preparation are summarized in Table 1.

Table 1. Conditions and phase composition of obtained materials

\begin{tabular}{|l|c|c|c|c|}
\hline Sample & $\mathrm{T}_{\text {activation }}[\mathrm{K}]$ & $\mathrm{SiO}_{2} / \mathrm{Al}_{2} \mathrm{O}_{3}$ & $\mathrm{Al}_{2} \mathrm{O}_{3} / \mathrm{Na}_{2} \mathrm{O}$ & $\begin{array}{l}\text { Solid } \\
\text { phase/ } \mathrm{H}_{2} \mathrm{O}\end{array}$ \\
\hline $\mathrm{A} 1$ & \multirow{2}{*}{368} & 2.00 & & \\
$\mathrm{~A} 2$ & & 2.25 & & \\
$\mathrm{A3}$ & & 2.50 & 1.00 & 1.25 \\
$\mathrm{~B} 1$ & & 2.00 & & \\
$\mathrm{~B} 2$ & 353 & 2.25 & & \\
$\mathrm{~B} 3$ & & 2.50 & & \\
\hline
\end{tabular}

\section{Material modification}

The sorption of heavy metal cations $\left(\mathrm{Ni}^{2+}, \mathrm{Zn}^{2+}, \mathrm{Cd}^{2+}\right.$ and $\mathrm{Pb}^{2+}$ ) was carried out with the $\mathrm{A} 1$ and $\mathrm{B} 1$ samples, because in the case of those samples, the most zeolite phases were obtained.

For this purpose, the materials were triturated to obtain a particle size below $0.125 \mathrm{~mm} .5 \mathrm{ml}$ of a salts as: $\mathrm{Cd}\left(\mathrm{NO}_{3}\right)_{2} \cdot 4 \mathrm{H}_{2} \mathrm{O}, \mathrm{Pb}\left(\mathrm{NO}_{3}\right)_{2}, \mathrm{Zn}\left(\mathrm{NO}_{3}\right)_{2} \cdot 6 \mathrm{H}_{2} \mathrm{O}$ and $\mathrm{NiSO}_{4} \cdot 7 \mathrm{H}_{2} \mathrm{O}\left(0.01 \mathrm{~mol} / \mathrm{dm}^{3}\right)$ was added to $0.1 \mathrm{~g}$ of the sample, shaken for $24 \mathrm{~h}$, centrifuged, washed three times with distilled water, and then dried.

\section{Research methodology}

The phase composition of the samples was investigated by XRD (PANalytical; $\mathrm{CuK}_{\alpha}$ radiation with a wavelength of $1.5406 \AA$ ). Measurements were performed in the 5-90 $2 \theta$ angle range (the presented diffractograms show the range from 5 to $40^{\circ}$ ) for $4 \mathrm{~h}$, with an 0.008 increment, using a graphite monochromator. Phases were identified using the HighScore Plus application and the ICDD (International Centre for Diffraction Data).

Qualitative and quantitative analysis of the parent material and the geopolymer samples before and after sorption were carried out with XRF (WDXRF, Axios Max 4 kW, PANalytical).

Low-temperature nitrogen sorption was performed with a Micromeritics ASAP 2000 device after $24 \mathrm{~h}$ of activation of the studied samples at $400^{\circ} \mathrm{C}$. The BET (Brunauer-Emmett-Teller) equation and was used for determination of the overall specific surface $\left(\mathrm{S}_{\mathrm{BET}}\right)$.

The microstructural analysis of the samples was performed using a scanning electron microscope (FEI Nova NanoSEM 200).

FT-IR spectra were measured with a vacuum spectrometer (Bruker VERTEX 70V), using the standard $\mathrm{KBr}$ (Merck) pellet method for mid-infrared (MIR). The spectra were recorded with a $4 \mathrm{~cm}^{-1}$ resolution, over the course of 128 scans.

\section{RESULTS AND DISCUSSION}

\section{Chemical composition}

According to the literature ${ }^{\mathbf{2} 21}$, the initial contents of Si, $\mathrm{Al}$ and $\mathrm{Na}$ allow the type and contribution of crystalline and amorphous phases to be controlled (Table 1). The parameters that have a significant impact on the final properties of geopolymers are $\mathrm{Si} / \mathrm{Al}$ and $\mathrm{Na} / \mathrm{Al}$ ratios. The former affects the dissolution, hydrolysis and condensation of geopolymerization reactions. The proposed values are in a range that ensures high strength and durability of the resulting products ${ }^{22}$.

\section{XRD studies}

During the calcination of kaolin, kaolinite transforms into amorphous metakaolinite ${ }^{\mathbf{2 3}}$. In the diffraction patterns of both sample series (A and B), no significant reflections originating from kaolinite phase were observed (Fig. 1). However, peaks indicating the presence of unreacted silica from the starting kaolin were present, as well as reflections originating from quartz ${ }^{24}$. With exception of B3 sample, among sodalite, zeolites X and $\mathrm{A}$, at least one was present in every sample which 
confirmed that geopolymerization enables the synthesis of zeolite phases sunk in the geopolymer matrix. The rise in the baseline (i.e. halo $-2 \theta=10-20^{\circ}$ ) indicates the expected amorphous component of the studied samples $^{2}$. This is more noticeable in the case of the A-serie (A1 and A2), which was activated at a higher temperature. Depending on the $\mathrm{SiO}_{2} / \mathrm{Al}_{2} \mathrm{O}_{3}$ molar ratio in the starting materials, and on the temperature of activation, various zeolite structures in an amorphous geopolymer matrix were obtained. For the B3 sample with a low aluminum content $(\mathrm{Si} / \mathrm{Al}=1.25)$, zeolite structures were not observed, unlike in the case of the A3 sample, which had the same composition, but was activated at a different temperature. According to the available reports ${ }^{24}$, the formation of zeolite structures is promoted only when both aluminum and sodium are present at high concentrations. It is worth mentioning that the initial water content affects the geopolymerization process, i.e. the structure and other properties of the obtained geopolymers ${ }^{25}$.

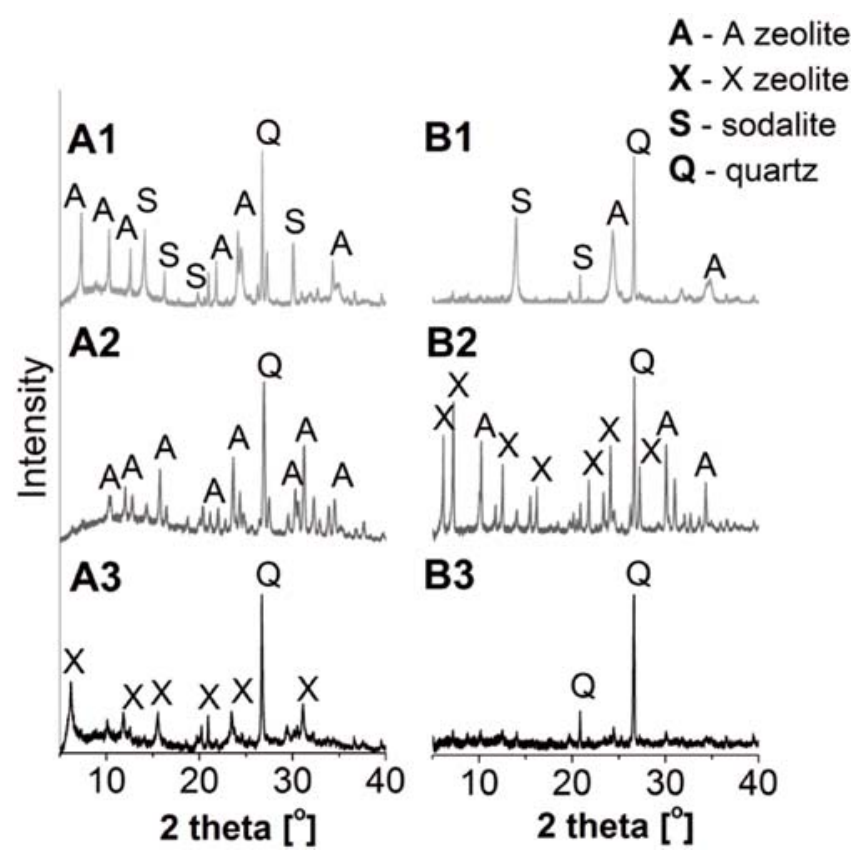

Figure 1. Diffraction patterns and phase compositions of the obtained geopolymers

\section{IR studies of geopolymers}

Figure 2 presents the mid-infrared (MIR) spectra for the aforementioned samples (series A and B). IR absorption spectra made it possible to obtain information about the structure of the zeolite samples after geopolymerization. Considering the chemical compositions of the starting material and of the materials after geopolymerization, $\mathrm{Si}-\mathrm{O}$ bond vibrations in the range of $1000-400 \mathrm{~cm}^{-1}$ could have been expected. However, the most interesting range is $800-500 \mathrm{~cm}^{-1}$, which is typical for vibrations of overtetrahedral structural units (i.e. single- or double-rings $)^{\mathbf{2 6}}$. For both series, intensive bands originating from the stretching vibrations of the $\mathrm{O}-\mathrm{H}$ groups were observed at $3490-3460 \mathrm{~cm}^{-1} 27$. The most intensive band was registered for materials with a $\mathrm{SiO}_{2} /$ $\mathrm{Al}_{2} \mathrm{O}_{3}$ ratio of 2.25 . The highest intensity of the band is related to the most of $\mathrm{OH}$ groups in the structure of this material, which may originate from zeolite forms or kaolinite hydration products (amorphous gel). The O-H bending vibrations at $1650 \mathrm{~cm}^{-1}$ are likely associated with the presence of weakly bound water molecules on the surface or in so-called zeolite cages ${ }^{28}$. The band at about $1450 \mathrm{~cm}^{-1}$ is associated with carbonate groups, which had most likely formed in the partial reaction between sodium hydroxide and atmospheric $\mathrm{CO}_{2}$ during the thermal activation of geopolymers ${ }^{29}$. This band is observed for both series of samples, and is particularly intensive for A1 and A3 samples, for which the analysis of diffraction patterns showed the presence of sodalite. The highest band intensity for the A3 sample is associated with the presence of large amounts of crystalline phases as well as sodium originating from sodium hydroxide, present during the geopolymerization reaction.

Intensive bands at $1200-400 \mathrm{~cm}^{-1}$, observed for all samples, correspond to the vibrations of Si-O-Si and Si-O-Al groups, typical of aluminosilicate structures. X-ray analysis revealed that the character of the samples was both amorphous and crystalline, with the latter related to the presence of zeolite (Fig. 1). The analysis of MIR spectra showed the presence of bands at 1010-990 $\mathrm{cm}^{-1}$, indicating asymmetrical stretching vibrations of $\mathrm{Si}-\mathrm{O}-\mathrm{Si}$ and $\mathrm{Al}-\mathrm{Si}-\mathrm{O}$ bonds in $\left[\mathrm{SiO}_{4}\right]$ and $\left[\mathrm{AlO}_{4}\right]$ tetrahedrons in the geopolymer framework ${ }^{\mathbf{3 0}}$.

Bands associated with occurrence of symmetrical vibrations, which allow the degree of polymerization to be determined, were noted at $900-500 \mathrm{~cm}^{-1}$. Depending on the position of pseudolattice vibrations corresponding to overtetrahedral structural units, bands specific to a given type of zeolite were registered ${ }^{31}$. Therefore, in the case of $\mathrm{A} 3$, characterized by $\mathrm{Si} / \mathrm{Al}=1.25$, bands at 880 and $750 \mathrm{~cm}^{-1}$ were recorded. Their presence results from the vibrations specific to D6R (six-membered rings) in the framework of zeolite X. Similar results were noted for $\mathrm{B} 2$, but the intensity of the band was low. The presence of the crystalline phase of zeolite A in samples A1, A2, $\mathrm{B} 1$ and $\mathrm{B} 2$ was confirmed. Thus, in the case of samples with average aluminum content (A2 and B2), the oscillation band of double four-membered rings $\left(560 \mathrm{~cm}^{-1}\right)$ presented in the structure of zeolite A was observed ${ }^{\mathbf{3 2}}$. This band exhibited the highest intensity only in the case of these materials. The bands specific to vibrations of double four-membered rings (D4R) are also observed for A1 and B1, but their intensity is low. In the case of samples with low aluminum content (A3 and B3), for which no peaks specific to the crystalline phase of zeolite A were recorded in the diffraction patterns, the $560 \mathrm{~cm}^{-1}$ band was observed. This can be related to the condensation of tetrahedra to D4R, which is one of the presumed mechanisms of the formation of zeolite structures ${ }^{33}$.

The bands at $700 \mathrm{~cm}^{-1}$ were also analyzed. Their presence indicates that the generated geopolymer structure formed as a result of a reaction between aluminosilicate and the alkali solution. This is the reason for the presence of the Si-O-T ( $\mathrm{T}=\mathrm{Si}$ or $\mathrm{Al}$ ) band, which was especially pronounced in the case of the A1 and B1 samples, but is also observed for other materials.

A certain correlation between the positions and intensities of bands and the $\mathrm{SiO}_{2} / \mathrm{Al}_{2} \mathrm{O}_{3}$ ratios can be noted (Fig. 2). For higher concentrations of silica in the geopolymer structure, all bands shift towards lower frequencies and their intensity increases. 

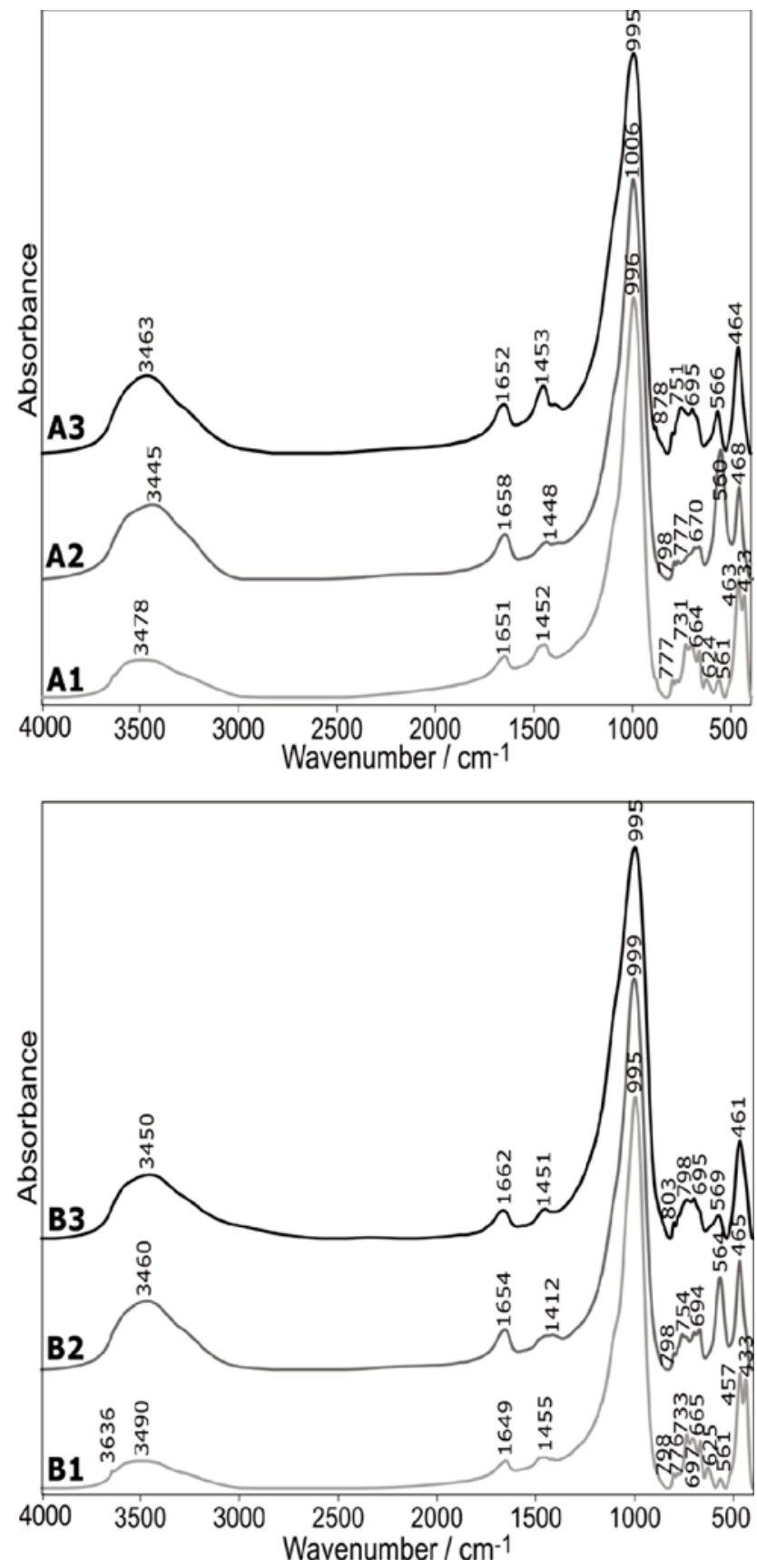

Figure 2. IR spectra of the obtained geopolymers

\section{Physicochemical studies}

The BET results showed that the most developed surface was observed for the samples activated at high temperature $\left(\mathrm{S}_{\mathrm{BET}(\mathrm{A} 2)}=262\right.$ and $\left.\mathrm{S}_{\mathrm{BET}(\mathrm{A} 3)}=115 \mathrm{~m}^{2} / \mathrm{g}\right)$. The only B-serie samples for which considerable surface area was observed was $\mathrm{B} 2\left(\mathrm{~S}_{\mathrm{BET}(\mathrm{B} 2)}=46 \mathrm{~m}^{2} / \mathrm{g}\right)$. The $\mathrm{A} 1$ $\left(5 \mathrm{~m}^{2} / \mathrm{g}\right)$ and $\mathrm{B} 1\left(7 \mathrm{~m}^{2} / \mathrm{g}\right)$ samples exhibited relatively low values. The smallest surface area equal to about $3 \mathrm{~m}^{2} / \mathrm{g}$ was observed for B3 sample. This is likely due to the occurrence of a compact matrix with densely occurring small pores. In the case of materials that had a large specific surface area, high values of $\mathrm{S}_{\text {micro }}\left(\mathrm{S}_{\text {micro(A2) }}=\right.$ $241, \mathrm{~S}_{\text {micro(A3) }}=100, \mathrm{~S}_{\text {micro(B2) }}=41 \mathrm{~m}^{2} / \mathrm{g}$ ) were found. One of the implications is the presence of multiple active sites with the ability to bind to metal ions ${ }^{34}$.

Figure 3 shows the SEM images of representative samples from each series: A1 and B1, activated at 368 and $353 \mathrm{~K}$, respectively. The micrographs show the homogeneous character of the studied samples. The surface of geopolymers is built of homogeneously and regularly distributed particles with a spherical shape. Fine spherical crystals of sodalite ( 1 at the picture) and cubic grains of zeolite A (2 at the picture) were observed. The grains form large agglomerates, and the size of an individual grain in both cases is comparable, i.e. about 1-2 $\mu \mathrm{m}$. For the remaining samples (data not shown), the same trend was observed.
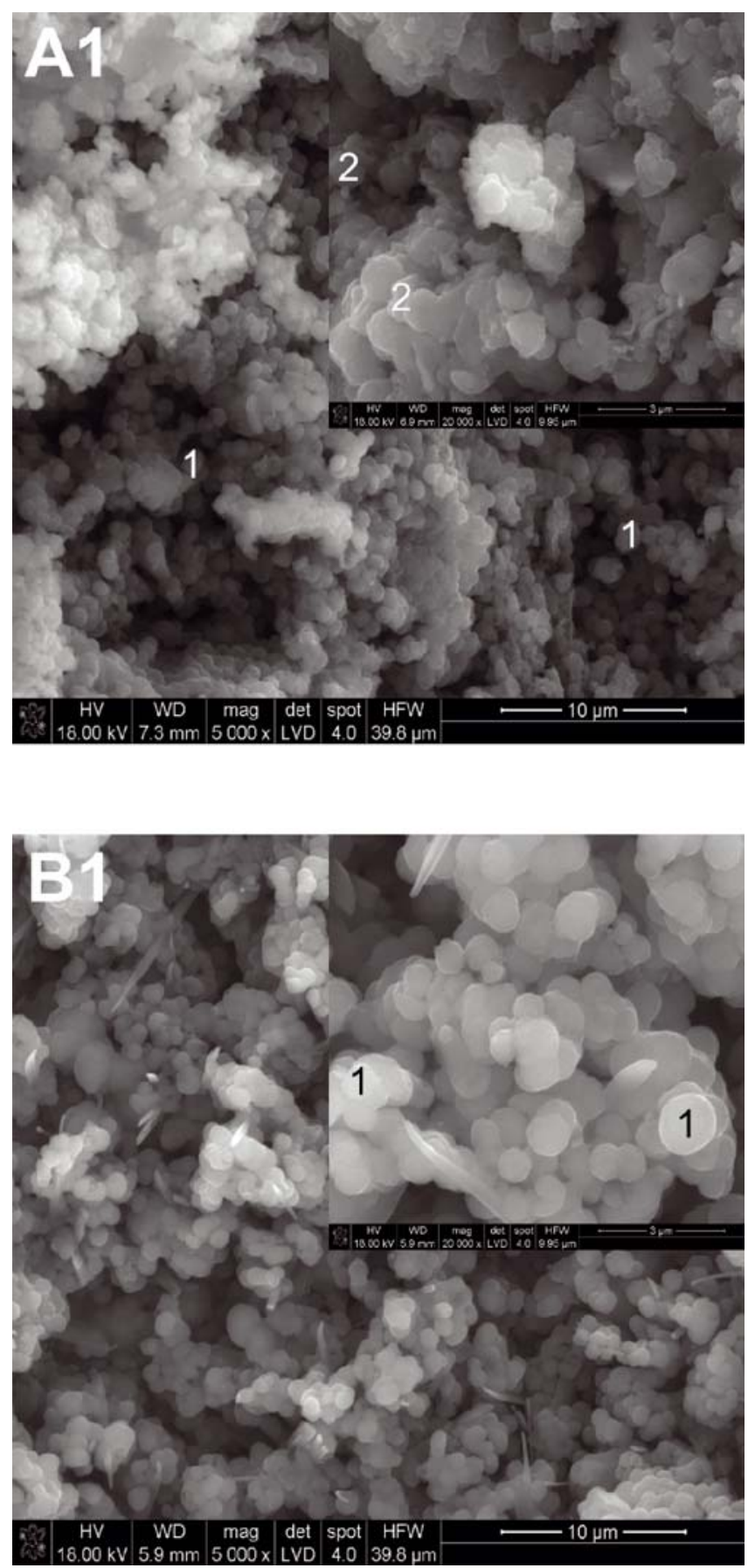

Figure 3. SEM micrographs of geopolymers respectively from samples A1 and B1

IR studies of sorption of heavy metal cations on geopolymers

The sorption of heavy metal cations from aqueous metal salts was carried out for the A1 and B1 samples. The registered spectra are presented in Figure 4.

According to Mozgawa ${ }^{35}$, the immobilization of heavy metals causes noticeable changes in IR spectra. A cursory analysis of the MIR spectra (Fig. 4) recorded for the investigated geopolymer materials after the sorption 

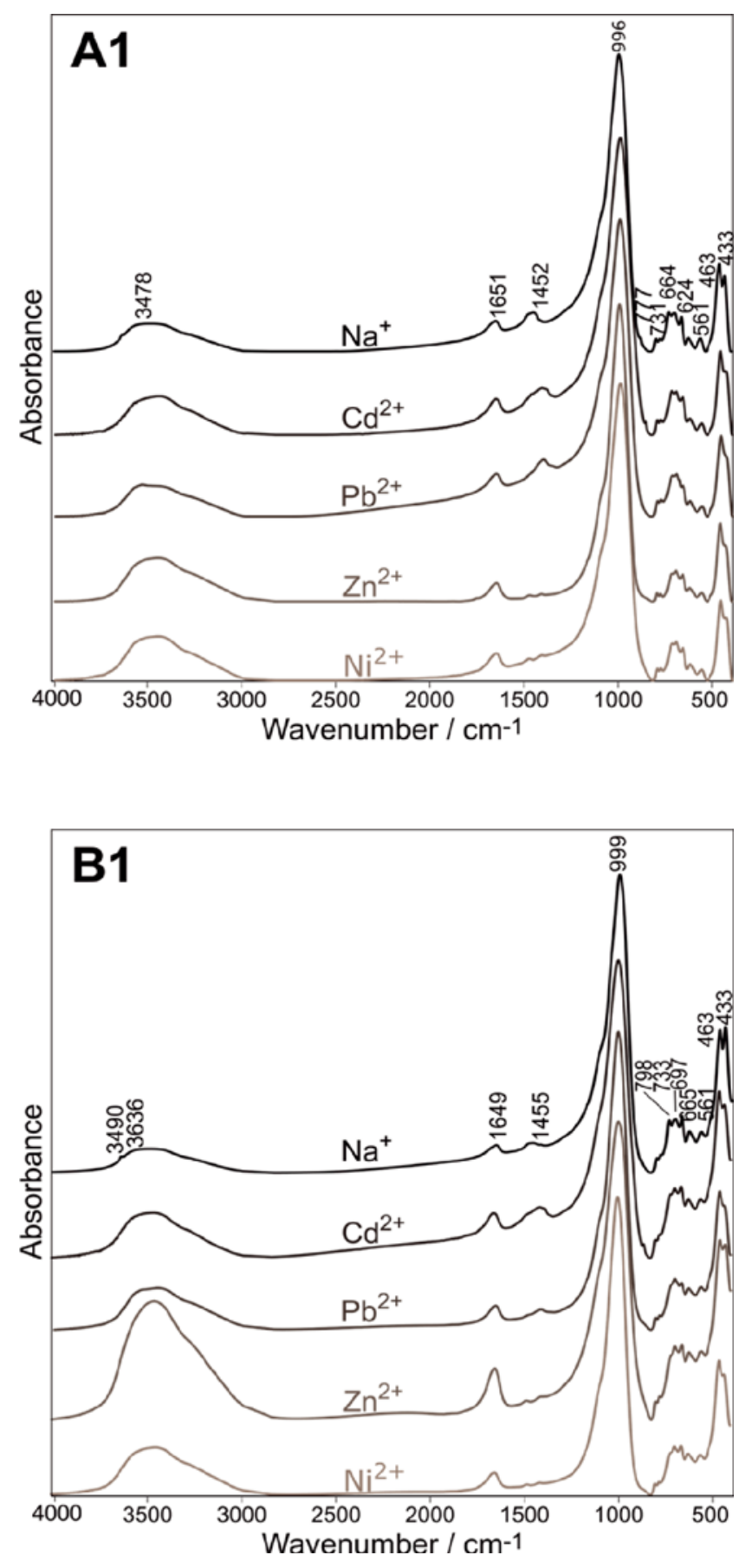

Figure 4. IR spectra after sorption of heavy metal cations on $\mathrm{A} 1$ and B1 samples of heavy metal cations indicates that they do not differ significantly. Changes related to vibrations originating from $\mathrm{O}-\mathrm{H}$ groups should be observed in the frequency range of $3100-3700 \mathrm{~cm}^{-1}$. This band is composed of several bands of varying nature and location within the zeolite framework, including bands corresponding to silanol $(\mathrm{Si}-\mathrm{OH})$ group/bond vibrations on the surface of grains or on the surface of mesopores, silanol groups/ bonds in framework defects, and bridged acid groups $(\mathrm{Si}-\mathrm{OH}-\mathrm{Al})^{\mathbf{3 6}}$. The impact of the sorbed cations on the geopolymer structure is clear when the fragments of spectra in a narrower range of wavenumbers (700-500 $\mathrm{cm}^{-1}$ ) are compared (Fig. 4). For B1 sample a considerable increase in the intensity of bands corresponding to particular ions is observed, in the following order: $\mathrm{Pb}^{2+}<\mathrm{Cd}^{2+}<\mathrm{Zn}^{2+}<\mathrm{Ni}^{2+}$. When comparing the band intensities with the size of the ionic radii $\left(\mathrm{Na}^{+}-116\right.$ ppm, $\mathrm{Pb}^{2+}-133$ ppm, $\mathrm{Cd}^{2+}-109$ ppm, $\mathrm{Zn}^{2+}-88$ ppm, $\left.\mathrm{Ni}^{2+}-72 \mathrm{ppm}\right)$, the following correlation can be noted: the decrease in the size of cationic radii is accompanied by an increase in the intensity of the bands corresponding to stretching vibrations of $\mathrm{OH}$ groups. In the case of the A1 sample, the observed dependence is different: $\mathrm{Cd}^{2+}<\mathrm{Zn}^{2+}<\mathrm{Ni}^{2+}<\mathrm{Pb}^{2+}$. These changes may be connected to the different nature of cations that coordinate hydroxyl groups, and, more specifically, their behavior in aqueous media. This is the result of hydration and the difference in the tendency of the analyzed cations to form water complexes in an aqueous environment.

In the range of pseudolattice vibrations (800-600 $\mathrm{cm}^{-1}$ ) for all materials, clear shifts of bands towards lower frequencies and a slight change in intensities were observed. Changes in IR spectra occur because of the exchange of $\mathrm{Na}^{+}$ions with heavy metal cations ${ }^{37}$. Ion exchange causes changes in the space surrounding the ring, the charge and radius of cations, and the deformation of the ring.

The observed changes in the IR spectra were confirmed via the chemical composition analysis (values in percentage terms) performed both before and after the sorption of heavy metals (Table 2). The composition of the studied samples changed after the sorption of selected cations. These materials may subsequently find potential use in the sorption of heavy metals from aqueous solutions.

Table 2. Chemical composition of geopolymers before and after the sorption of heavy metal cations

\begin{tabular}{|c|c|c|c|c|c|c|c|c|c|}
\hline \multirow{2}{*}{ Chemical composition } & \multicolumn{5}{|c|}{ A1 } & \multicolumn{4}{|c|}{ B1 } \\
\hline & 0 & $\mathrm{Ni}$ & $\mathrm{Zn}$ & $\mathrm{Cd}$ & $\mathrm{Pb}$ & 0 & $\mathrm{Ni}$ & $\mathrm{Zn}$ & $\mathrm{Cd}$ \\
\hline $\mathrm{SiO}_{2}$ & 53.31 & 35.69 & 35.77 & 35.20 & 35.66 & 53.31 & 36.46 & 34.81 & 35.91 \\
\hline $\mathrm{TiO}_{2}$ & 0.51 & 0.31 & 0.30 & 0.26 & 0.26 & 0.51 & 0.29 & 0.27 & 0.24 \\
\hline $\mathrm{Al}_{2} \mathrm{O}_{3}$ & 42.49 & 31.16 & 30.38 & 31.80 & 31.29 & 42.49 & 31.84 & 30.87 & 32.22 \\
\hline $\mathrm{Fe}_{2} \mathrm{O}_{3}$ & 0.43 & 0.26 & 0.27 & 0.23 & 0.23 & 0.43 & 0.22 & 0.23 & 0.22 \\
\hline $\mathrm{CaO}$ & 0.07 & 0.18 & 0.16 & 0.11 & 0.13 & 0.07 & 0.07 & 0.07 & 0.08 \\
\hline $\mathrm{MgO}$ & 0.14 & 0.19 & 0.12 & 0.14 & 0.14 & 0.14 & 0.14 & 0.12 & 0.13 \\
\hline $\mathrm{NiO}_{2}$ & 0.01 & 2.98 & 0.00 & 0.00 & 0.01 & 0.01 & 2.74 & 0.01 & 0.01 \\
\hline $\mathrm{CuO}_{2}$ & 0.00 & 0.54 & 0.01 & 0.01 & 0.03 & 0.00 & 0.01 & 0.01 & 0.01 \\
\hline $\mathrm{ZnO}_{2}$ & 0.00 & 0.01 & 2.28 & 0.01 & 0.01 & 0.00 & 0.00 & 2.23 & 0.01 \\
\hline $\mathrm{CdO}_{2}$ & 0.00 & 0.00 & 0.00 & 0.51 & 0.00 & 0.00 & 0.00 & 0.00 & 0.52 \\
\hline $\mathrm{PbO}_{2}$ & 0.05 & 0.02 & 0.02 & 0.03 & 3.81 & 0.05 & 0.02 & 0.02 & 0.01 \\
\hline $\mathrm{Na}_{2} \mathrm{O}$ & 1.96 & 27.88 & 30.06 & 30.86 & 27.80 & 1.96 & 27.57 & 30.72 & 30.08 \\
\hline $\mathrm{K}_{2} \mathrm{O}$ & 0.57 & 0.31 & 0.30 & 0.41 & 0.25 & 0.57 & 0.29 & 0.30 & 0.21 \\
\hline other & 0.46 & 0.47 & 0.33 & 0.43 & 0.38 & 0.46 & 0.35 & 0.34 & 0.35 \\
\hline
\end{tabular}




\section{CONCLUSIONS}

The study demonstrated that it is possible to synthesize composite geopolymer materials containing crystalline phases of zeolites. The selection of the appropriate synthesis conditions yielded zeolite structures, i.e. zeolites A and X as well as sodalite. The type of zeolite structure depends largely on the type of reagent $(\mathrm{Si} / \mathrm{Al}$ ratio) and the temperature of activation. A number of techniques, including infrared absorption spectroscopy (FT-IR), X-ray diffraction (XRD) and scanning electron microscopy (SEM) confirmed the presence of crystalline zeolite structures in the amorphous geopolymer matrix. An attempting to sorb selected heavy metals on the obtained materials confirmed their effectiveness in the adsorption of cations from aqueous solutions.

\section{ACKNOWLEDGMENTS}

This work was financially supported by the National Science Centre in Poland as part of grant no. 2015/17/B/ ST8/01200.

\section{LITERATURE CITED}

1. Davidovits, J. (1994). Geopolymers: man-made rock geosynthesis and the resulting development of very early high strength cement. J. Mater. Educ. 16(2-3), 91-139.

2. Yun-Ming, L., Cheng-Yong, H., Abdullah, M.M.A.B. \& Hussin, K. (2016). Structure and properties of clay-based geopolymer cements: A review. Prog. Mater. Sci. 83, 595-629. DOI: $10.1016 /$ j.pmatsci.2016.08.002.

3. Ilic, B.R., Mitroviv, A.A. \& Milicic, L.R. (2010). Thermal treatment of kaolin clay to obtain metakaolin. Hem. Ind. 64 (4), 351-356. DOI: 10.2298/HEMIND100322014I.

4. Liew, Y.M., Kamarudin, H., Mustafa Al Bakri, A.M., Luqman, M., Khairul Nizar, I., Ruzaidi, C.M. \& Heah, C.Y. (2012). Processing and characterization of calcined kaolin cement powder. Constr. Build. Mater. 30, 794-802. DOI: 10.1016/j. conbuildmat.2011.12.079.

5. San Cristóbal, A.G., Castelló, R., Martín Luengo, M.A. \& Vizcayno, C. (2010). Zeolites prepared from calcined and mechanically modified kaolins: a comparative study. Appl. Clay Sci. 49(3), 239-246. DOI: 10.1016/j.clay.2010.05.012.

6. Xu, H. \& van Deventer, J.S.J. (2002). Geopolymerization of multiple minerals. Miner. Eng. 15(12), 1131-1139. DOI: 10.1016/S0892-6875(02)00255-8.

7. Xu, H. \& van Deventer, J.S.J. (2000). The geopolymerisation of alumino-silicate minerals. Int. J. Miner. Process. 59(3), 247-266. DOI: 10.1016/S0301-7516(99)00074-5.

8. Pacheco-Torgal, F., Castro-Gomes, J.P. \& Jalali, S. (2008). Alkali-activated binders: a review. Part 2. About materials and binders manufacture. J. Constr. Build. Mater. 22(7), 1315-1322. DOI: 10.1016/j.conbuildmat.2007.03.019.

9. Palomo, A., Grutzek, M.W. \& Blanco-Varela, M.T. (1999). Alkali-activated fly ashes. A cement for the future. Cem. Concr. Res. 29(8), 1323-1329. DOI: 10.1016/S0008-8846(98)00243-9.

10. Alonso, S. \& Palomo, A. (2001). Alkaline activation of metakaolin and calcium hydroxide mixtures: influence of temperature, activator, concentration and solids ratio. Mater. Lett. 47(1-2), 55-62. DOI: 10.1016/S0167-577X(00)00212-3.

11. Alonso, S. \& Palomo, A. (2001). Calorimetric study of alkaline activation of calcium hydroxide-metakaolin solid mixtures. Cem. Concr. Res. 31(1), 25-30. DOI: 10.1016/S00088846(00)00435-X.

12. Davidovits, J. (2015). Geopolymer Chemistry and Applications (4th ed.). Saint-Quentin, France: Institut Géopolymère
13. Provis, J.L. \& van Deventer, J.S.J. (2009). Geopolymers: Structure, processing, properties and industrial applications (1st ed.). Abingdon, UK: Woodhead Publishing Limited

14. Fernandez-Jimenez, A. \& Palomo, A. (2005). Chemical durability of geopolymers. In Provis, J.L. \& van Deventer (Eds.), Geopolymers: Structure, processing, properties and industrial applications (pp. 167-193). Abingdon, UK: Woodhead Publishing Limited.

15. Zheng, L., Wang, W. \& Shi, Y. (2010). The effects of alkaline dosage and $\mathrm{Si} / \mathrm{Al}$ ratio on the immobilization of heavy metals in municipal solid waste incineration fly ash-based geopolymer. Chemosphere 79(6), 665-671. DOI: 10.1016/j. chemosphere.2010.02.018.

16. Ge, Y., Cui, X., Kong, Y., Li, Z., He, Y. \& Zhou, Q. (2015). Porous geopolymeric spheres for removal of $\mathrm{Cu}(\mathrm{II})$ from aqueous solution: Synthesis and evaluation. J. Hazard. Mater. 283, 244-251. DOI: 10.1016/j.jhazmat.2014.09.038.

17. Li, L., Wang, S. \& Zhu, Z. (2006). Geopolymeric adsorbents from fly ash for dye removal from aqueous solution. J. Colloid. Interf. Sci. 300(1), 52-59. DOI: 10.1016/j.jcis.2006.03.062

18. Zhang, J., Provis, J.L., Feng, D. \& Van Deventer, J.S.J. (2008a). Geopolymers for immobilization of $\mathrm{Cr}^{6+}, \mathrm{Cd}^{2+}$, and $\mathrm{Pb}^{2+}$. J. Hazard. Mater. 157(2-3), 587-598. DOI: 10.1016/j. jhazmat.2008.01.053.

19. Yousef, R.I., El-Eswed, B., Alshaaer, M., Khalili, F. \& Khoury, H. (2009). The influence of using Jordanian natural zeolite on the adsorption, physical, and mechanical properties of geopolymers products. J. Hazard. Mater. 165(1-3), 379-387. DOI: 10.1016/j.jhazmat.2008.10.004.

20. López, F.J., Sugita, S., Tagaya, M. \& Kobayashi, T. (2014). Metakaolin-Based Geopolymers for Targeted Adsorbents to Heavy Metal Ion Separation. J. Mater. Sci. Chem. Eng. 2, 16-27. DOI: $10.4236 /$ msce.2014.27002.

21. De Silva, P. \& Sagoe-Crenstil, K. (2008). The effect of $\mathrm{Al}_{2} \mathrm{O}_{3}$ and $\mathrm{SiO}_{2}$ on setting and hardening of $\mathrm{Na}_{2} \mathrm{O}-\mathrm{Al}_{2} \mathrm{O}_{3}-\mathrm{SiO}_{2}-$ $\mathrm{H}_{2} \mathrm{O}$ geopolymer system. J. Aust. Ceram. Soc. 44(1), 39-46.

22. Davidovits, J. (1982). U.S. Patent No. 4,349,386. United States: U.S. Patent and Trademark Office.

23. Kenne Diffo, B.B., Elimbi, A. Cyr, M., Dika Manga, J. \& Tchakoute Kouamo, H. (2015). Effect of the rate of calcination of kaolin on the properties of metakaolin-based geopolymers. J. Asian Ceram. Soc. 3(1), 130-138. DOI: 10.1016/j. jascer.2014.12.003.

24. Król, M., Minkiewicz, J. \& Mozgawa, W. (2016). IR spectroscopy studies of zeolites in geopolymeric materials derived from kaolinite. J. Mol. Struct. 1126, 200-206. DOI: 10.1016/j.molstruc.2016.02.027.

25. Zuhua, Z., Xiao, Y., Huajun, Z. \& Yue, C. (2009). Role of water in the synthesis of calcined kaolin-based geopolymer. Appl. Clay Sci. 43(2), 218-223. DOI: 10.1016/j.clay.2008.09.003.

26. Mozgawa, W. (2007). Vibrational Spectroscopy of Zeolites. Habilitation dissertation, AGH University of Science and Technology, Krakow, Poland.

27. Rattanasak, U. \& Chindaprasirt, P. (2009). Influence of $\mathrm{NaOH}$ solution on the synthesis of fly ash geopolymer. Miner. Eng. 22(12), 1073-1078. DOI: 10.1016/j.mineng.2009.03.022.

28. Heah, C.Y., Kamarudin, H., Mustafa Al Bakri, A.M., Bnhussain, M., Luqman, M. \& Khairul Nizar, I. (2012). Study on solids-to-liquid and alkaline activator ratios on kaolin-based geopolymers. Constr. Build Mater. 35, 912-922. DOI: 10.1016/j. conbuildmat.2012.04.102.

29. Andini, S., Cioffi, R., Colangelo, F., Grieco, T., Montagnaro, F. \& Santoro, L. (2008). Coal fly ash as raw material for the manufacture of geopolymer-based products. Waste Manage. 28(2), 416-423. DOI: 10.1016/j.wasman.2007.02.001.

30. Gougazeh, M. \& Buhl, J.C. (2014). Synthesis and characterization of zeolite A by hydrothermal transformation of natural Jordanian kaolin. Appl. Clay Sci. 15, 35-42. DOI: 10.1016/j.jaubas.2013.03.007. 
31. Flaningen, E.M., Khatami, H. \& Szymański, H.A. (1974). Infrared structural studies of zeolite frameworks. Adv. Chem. Ser. 101, 201-229. DOI: 10.1021/ba-1971-0101.ch016.

32. Mikuła, A., Król, M. \& Koleżyński, A. (2015). The influence of the long-range order on the vibrational spectra of structures based on sodalite cage. Spectrochim. Acta A. 144, 273-280. DOI: 10.1016/j.saa.2015.02.073.

33. Cundy, C.S. \& Cox, P.A. (2005). The hydrothermal synthesis of zeolites: precursors, intermediates and reaction mechanism. Micropor. Mesopor. Mat. 82(1-2), 1-78. DOI: 10.1016/j.micromeso.2005.02.016.

34. Tang, Q., Ge, Y.Y., Wang, K.T., He, Y. \& Cui, X.M. (2015). Preparation and characterization of porous metakaolin-based inorganic polymer spheres as an adsorbent. Mater. Design. 88, 1244-1249. DOI: 10.1016/j.matdes.2015.09.126.

35. Mozgawa, W., Król, M. \& Bajda, T. (2009). Application of IR spectra in the studies of heavy metal cations immobilization on natural sorbents. J. Mol. Struct. 924-926, 427-433. DOI: 10.1016/j.molstruc.2008.12.028.

36. Góra-Marek, K. \& Datka, J. (2006). IR studies of OH groups in mesoporous aluminosilicates. Appl. Catal. A. 302 (1), 104-109. DOI: 10.1016/j.apcata.2005.12.027.

37. Król, M., Mozgawa, W., Barczyk, K., Bajda, T. \& Kozanecki, M. (2013). Changes in the vibrational spectra of zeolites due to sorption of heavy metal cations. J. Appl. Spectrosc. 80 (5), 644-650. DOI: 10.1007/s10812-013-9821-5. 